\title{
Role of dopamine-adenosine interactions in the brain circuitry regulating effort-related decision making: insights into pathological aspects of motivation
}

\author{
John D Salamone ${ }^{11}$, Merce Correa ${ }^{1,2}$, Andrew M Farrar ${ }^{3}$, Eric J Nunes ${ }^{1}$ \\ \& Lyndsey E Collins' \\ 'Division of Behavioral Neuroscience, Department of Psychology, University of Connecticut, Storrs \\ CT 06269-7020, USA \\ 2Department Psicologia, Universitat Jaume I, Castello, Spain \\ ${ }^{3}$ Center for Molecular \& Behavioral Neuroscience, Rutgers University, NJ, USA \\ †Author for correspondence: Tel. : +1 8604864302 = Fax: +1 8604862760 m john.salamone@uconn.edu
}

Brain dopamine, particularly in the nucleus accumbens, has been implicated in activational aspects of motivation and effort-related processes. Accumbens dopamine depletions reduce the tendency of rats to work for food, and alter effort-related decision making, but leave aspects of food motivation such as appetite intact. Recent evidence indicates that the purine neuromodulator adenosine, largely through actions on adenosine $A_{2 A}$ receptors, also participates in regulating effort-related processes. Adenosine $A_{2 A}$ antagonists can reverse the effects of dopamine $D_{2}$ antagonists on effort-related choice, and intraaccumbens injections of adenosine $A_{2 A}$ agonists produce effects that are similar to those induced by accumbens dopamine depletion or antagonism. These studies have implications for the understanding and treatment of energy-related disorders such as anergia and fatigue in psychiatry and neurology.

\section{Dopaminergic involvement in}

\section{activational aspects of motivation}

Similar to other psychological constructs such as emotion and cognition, motivation is not a simple or unitary phenomenon. Motivation is a complex and multifacted process that includes many diverse components. Some aspects of motivation are related to sensations of internal and external stimuli, while other aspects of motivation are related to motor function [1]. Motivated behavior takes place in phases that represent different degrees of physical or psychological distance from the primary motivational stimulus (i.e., appetitive vs consummatory; instrumental vs consummatory; see [2-4]). Moreover, motivation theory and research has emphasized for several years that there are 'directional' and 'activational' aspects of motivation [5-7]. Directional aspects refer to the observation that the behavior of animals is directed towards or away from particular motivational stimuli. In addition, it is evident that motivated behavior can be characterized by persistence, vigor and high levels of work output; these activational aspects of motivated behavior are highly adaptive because they enable organisms to overcome challenges or work-related response costs that separate them from significant stimuli such as food $[4,8-13]$. While foraging in the wild, animals can invest considerable time and can cover large areas of space in order to gain access to food or other primary motivational stimuli. Laboratory experiments have shown that animals can climb barriers, run in mazes or press levers on schedules with high input ratio requirements, in order to gain access to motivational stimuli such as food. Under some conditions the presentation of motivational stimuli can generate heightened, even excessive, levels of motor activity. In humans, impairments in behavioral activation can manifest themselves as energy-related symptoms such as psychomotor slowing, anergia and fatigue, which are features of depression, and can also be observed in other psychiatric or neurological disorders [11].

In addition to studying these behavioral processes involved in activational aspects of motivation, neuroscientists have also focused upon the brain mechanisms that are potentially involved. Several brain areas have been investigated, but one of the neural systems most closely associated with behavioral activation is the dopamine (DA) innervation of the nucleus accumbens $[8-11,14,15]$. Although the mesolimbic DA system has consistently been linked to aspects of drug reinforcement, and is often referred to as some type of 'pleasure' or 'reward' center, recent

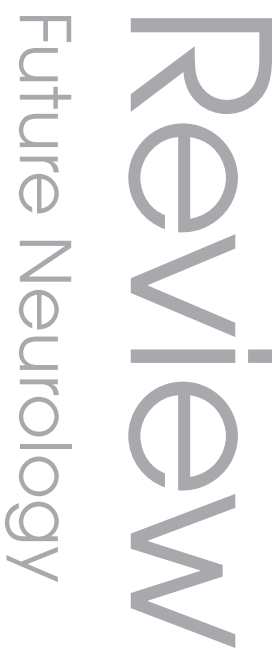

\section{Keywords}

- accumbens $=$ anergia

- behavioral activation

- dopamine = fatigue

- motivation

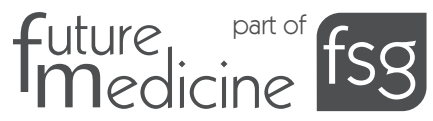


research has demonstrated that the story is much more complicated and there are signs of a 'paradigm shift' taking place in this field $[11,16]$. In fact, neither DA antagonists, whole forebrain DA depletions or localized DA depletions in nucleus accumbens affect appetitive taste reactivity for food [17-20]; these findings have consistently been interpreted to suggest that interference with mesolimbic DA transmission does not blunt the hedonic reaction to food (i.e., 'liking'). Although Gunne and colleagues reported that the hedonic effects of amphetamine could be blocked by $\mathrm{DA} \mathrm{D}_{2}$ receptor antagonism [21], considerable research has failed to support this hypothesis [22-24]. The $\mathrm{D}_{1}$ antagonist ecopipam did not blunt either the self-administration or the subjective pleasure induced by cocaine $[25,26]$. In addition, catecholamine depletion induced by feeding individuals a phenylalanine/tyrosinefree diet did not reduce cocaine-induced hedonia or self-administration [27]. In this context, it is worth noting that substantial literature has linked nucleus accumbens in general, and its DA innervation in particular, to aspects of aversive learning, aversive motivation and stress [28-44]. It is generally recognized that whole forebrain DA depletions can produce aphagia (i.e., lack of eating); however, in animals, this effect has been conclusively linked to motor or sensorimotor impairments induced by depletions of DA in the lateral or ventrolateral caudate/putamen, but not to actions upon the nucleus accumbens [44-47]. Several papers have shown that nucleus accumbens DA depletions do not substantially impair appetite for food, or produce a broad disruption of directional aspects of primary food motivation [46-48]. Depletions of DA in nucleus accumbens failed to reduce food intake or feeding rate, and did not impair food handling, although similar depletions in the ventrolateral neostriatum did affect these measures of feeding [46]. DA $\mathrm{D}_{1}$ or $\mathrm{D}_{2}$ family antagonists injected into either the core or the shell subregions of nucleus accumbens impaired locomotion and rearing, but did not suppress food intake, which led Baldo et al. to conclude that DA receptor antagonism "did not abolish the primary motivation to eat" [49]. Several studies have demonstrated that nucleus accumbens DA depletions, as well as systemic or intra-accumbens DA antagonism, do not produce effects that closely resemble those resulting from motivational manipulations, such as prefeeding or appetite suppressant drugs [50-54]. Thus, despite claims to the contrary, nucleus accumbens DA has not been strongly implicated in food consumption, appetite or primary food motivation [13]. Similar arguments have been made with regard to other motivational conditions, including sexual and maternal behaviors [55-58].

By contrast, an enormous body of evidence demonstrates that nucleus accumbens DA is involved generally in behavioral activation and, more specifically, in effort-related aspects of food motivation. Accumbens DA depletions reduced spontaneous and novelty-induced locomotor activity and rearing, as well as stimulant-induced activity $[48,59,60]$. Behaviors such as excessive drinking, wheel-running or locomotor activity, which are induced by scheduled presentation of food pellets to food-deprived animals, were reduced by accumbens DA depletions [61-63]. Furthermore, the effects of nucleus accumbens DA depletions on food-reinforced instrumental behavior depend greatly upon the specific task requirements of the schedule of food reinforcement. Schedules with minimal work requirements, such as a fixed ratio (FR) 1 , and variable interval (VI) or progressive interval schedules, are relatively insensitive to the effects of accumbens DA depletions [59,64-72]. In fact, one of the critical factors that makes a food-reinforced operant task sensitive to the effects of accumbens DA depletions is the size of the ratio requirement (i.e., the number of times they have to press the lever to receive food); as ratio requirements get higher, rats become more sensitive to the response-suppressing effects of accumbens DA depletions [66-68,70-72]. The impact of ratio requirement as a factor that leads to increased sensitivity to the effects of accumbens DA depletions is not simply dependent upon the degree of intermittence in the schedule (i.e., the time spent with no primary reinforcers). While performance on VI 30, 60 or $120 \mathrm{~s}$ schedules was minimally affected by accumbens DA depletions, attachment of a ratio requirement (FR5 or 10) to the interval requirement made these schedules highly sensitive to the response-suppressing effects of accumbens DA depletions $[59,68]$. Together with studies of food intake, this pattern of results indicates that nucleus accumbens DA depletions leave fundamental aspects of appetite or primary food motivation intact, but reduce the tendency of the animals to work for food reinforcement.

\section{Accumbens dopamine \& effort-related decision making}

In a complex environment there may be several motivational stimuli available concurrently (e.g., different types of food), which can vary in terms 
of quantity or quality. Typically, there would also be diverse patterns of instrumental behavior that are necessary for obtaining access to each stimulus, with response requirements that vary in terms of time, work and other parameters. Thus, in order to adapt to these conditions, organisms must select between various alternatives, making effort-related decisions and allocating behavioral resources based upon numerous factors related to response cost and reinforcement value. In addition to being involved in the exertion of effort, nucleus accumbens DA also participates in the process of effort-related choice behavior.

A number of behavioral procedures have been developed that allow for the assessment of how animals allocate resources based upon analyses of reinforcement value and response cost. For example, a T-maze procedure was developed to assess the effects of accumbens DA depletions on response choice based upon task difficulty [73]. The two choice arms of the maze can have different reinforcement densities (e.g., four vs two food pellets, or four vs zero), and in order to provide an effort-related challenge, a 44-cm barrier can be placed in the arm with the higher density of food reinforcement (FIGURE 1). When no barrier is present in the arm with the high reinforcement density, rats strongly prefer that arm, and neither haloperidol nor accumbens DA depletion alters their response choice [73]. When the arm with the barrier contained four food pellets, but the other arm contained no pellets, so that the only way to obtain food was by climbing the barrier, rats with accumbens DA depletions still chose the high-density arm, climbed the barrier and consumed the pellets [74]. These control experiments indicated that interference with DA transmission did not impair memory for which arm had the most pellets, did not affect the discrimination of reinforcement density and did not alter arm preference. Nevertheless, low doses of DA antagonists and accumbens DA depletions dramatically altered choice behavior when the high-density arm (four pellets) had the barrier in place, and the arm without the barrier contained an alternative food source (two pellets). Under these conditions, rats with impaired DA transmission showed decreased choice for the high-density arm that contained the barrier, and increased choice for the arm with less food that did not have a barrier [73-75]. More recently, a mouse version of the T-maze task has been developed [76]. As with rats, the DA antagonist haloperidol decreased selection of the arm with the barrier in mice, but increased selection of the arm with no barrier, which contained a lower density of food reward. Interestingly, the same doses of haloperidol had no effect on choice when both arms were blocked by barriers; this observation confirms that the haloperidol-treated mice were capable of climbing the barrier, and remembered which arm had the higher density of reward, but these mice chose not to climb the barrier when there was an alternative food source available that could be reached with less effort. Taken together, these experiments indicate that accumbens DA depletions cause animals to reallocate their instrumental responses based upon the response requirements of the task (reviewed in [8-11,77]).

Another task that has been developed is an operant concurrent choice procedure that offers rats a choice between lever pressing to obtain a preferred food (high carbohydrate pellets), versus approaching and consuming a less preferred food (laboratory chow) that is concurrently available. Under baseline or control conditions, rats responding on FR1 or FR5 schedules typically get most of their food by lever pressing, and they eat minimal quantities of chow. However, lowto-moderate doses of DA antagonists with varying degrees of selectivity produce a substantial alteration of response allocation. The DA antagonists cis-flupenthixol, haloperidol, raclopride, eticloprided, SCH 23390, SKF83566 and ecopipam (SCH 39166) all decreased lever pressing for food but substantially increased intake of the concurrently available chow $[51,53,54,77,78]$. By contrast, knockdown of the DA transporter in mice resulted in the opposite effect; that is, increases in lever pressing and decreases in chow intake [79]. The nucleus accumbens, rather than the neostriatum, is the DA terminal region most closely associated with the effects of DA depletion or antagonism. Ventrolateral neostriatal DA depletions produced severe motor impairments that merely decreased both types of behavior, while injections of 6-hydroxydopamine into the anteroventromedial neostriatum were ineffective [80]. Decreases in lever pressing and increases in chow intake were produced by accumbens DA depletions, as well as by intra-accumbens injections of $\mathrm{D}_{1}$ or $\mathrm{D}_{2}$ family antagonists [51,66,80-84]. The shift from lever pressing to chow intake on this task has been demonstrated to occur if injections of $\mathrm{D}_{1}$ or $\mathrm{D}_{2}$ family antagonists were administered into the medial core, lateral core or dorsomedial shell subregions of the accumbens [51,82-84]. Although injections of the $\mathrm{D}_{2}$ antagonist, eticlopride, into nucleus accumbens core shifted behavior from lever pressing to chow intake, injections into a dorsomedial neostriatal control site were ineffective [84]. Thus, despite the fact that lever pressing is decreased by accumbens 


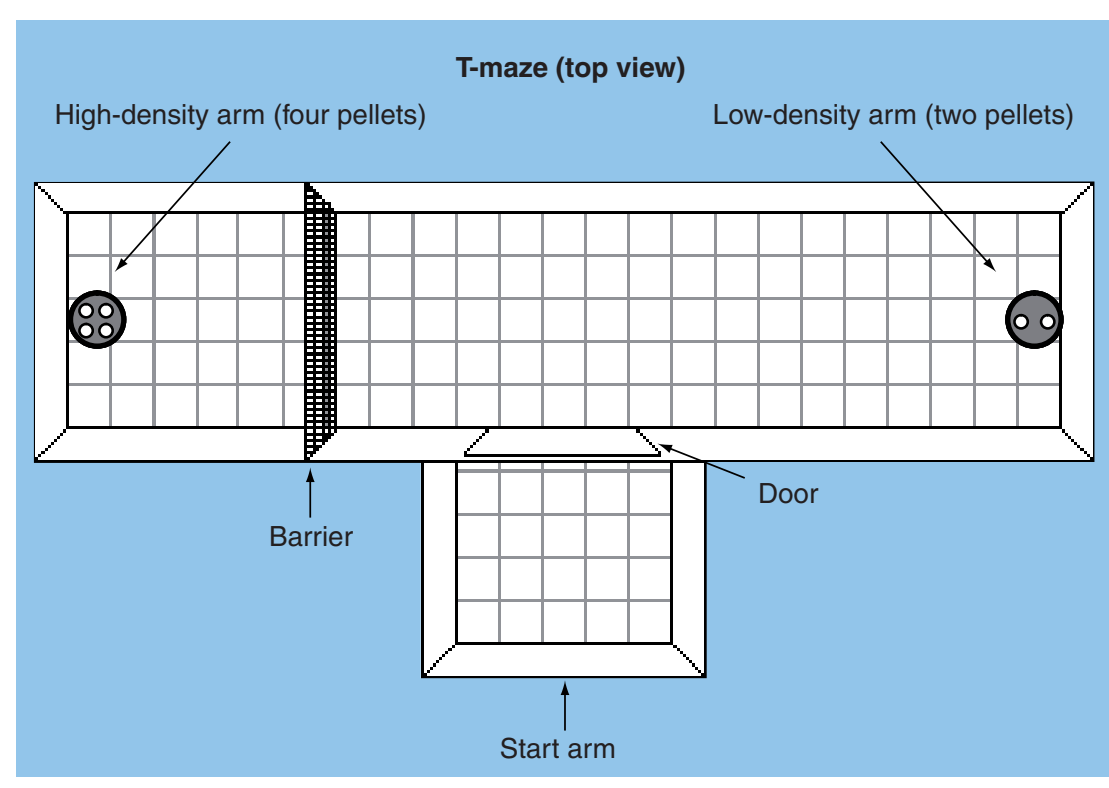

Figure 1. Top view of the T-maze apparatus used in the Mott et al. 2009 study. The start arm of the maze consisted of an enclosed plexiglas box $(29 \times 21 \times$ $21 \mathrm{~cm}$ ) with a wire mesh floor grid. The test arm of each side of the maze was a box $99 \times 32 \times 59 \mathrm{~cm}$. The test arm and back walls of the maze were constructed out of Plexiglas ${ }^{\circledR}$, and the floor was wire mesh. The doorway from the start arm to the maze was a stainless steel guillotine door. The barrier (depicted in the highdensity arm, to the left) was constructed of wire mesh $(44 \times 32 \mathrm{~cm})$. The highdensity arm contained four food pellets, and the low-density arm contained two food pellets.

Taken from [75]. free-feeding choice tests indicated that preference for the pellets over the laboratory chow, as well as food intake, were not affected by the various conditions that produce the shift from lever pressing to chow intake; this includes administration of low doses of haloperidol [51], as well as intra-accumbens injections of sulpiride or $\mathrm{SCH}$ 23390 [82]. With rats performing on the concurrent choice task, prefeeding to reduce food motivation was demonstrated to suppress both lever pressing and chow intake [51]. Although DA antagonists have been shown to reduce FR 5 lever pressing and increase chow intake, appetite suppressants such as fenfluramine and cannabinoid CB1 antagonists showed a very different pattern of effects [33,54], and did not increase chow intake at doses that suppress lever pressing. Together with the other results (reviewed previously), these findings demonstrate that interference with DA transmission does not simply reduce appetite for food.

In summary, animals administered low doses of DA antagonists, or those with accumbens DA depletions, remain directed towards the acquisition and consumption of food. Furthermore, they do not show severe impairments in motor capacity. Nevertheless, they manifest a reduced tendency to work for food, and their choice behavior is altered such that they become biased towards obtaining food through responses that have lower work-related costs. Thus, rats with impaired accumbens DA transmission switch from lever pressing for preferred food pellets to approaching and consuming the less preferred chow, and they switch from climbing the barrier to obtain the higher density of food reinforcement towards the alternative arm of the maze, which has less food that can be obtained with a lower degree of effort. The results of these studies are consistent with recent papers demonstrating that DA antagonists also affect effort discounting [87,88]. Bardgett et al. developed an effort-discounting version of the T-maze task [88], in which the amount of food in the high-density arm of the maze was diminished every time the rats selected that arm. Their results demonstrated that both the $\mathrm{D}_{1}$ family antagonist $\mathrm{SCH} 23390$ and the $\mathrm{D}_{2}$ family antagonist haloperidol altered effort discounting, making it more likely that rats would choose the arm with the smaller reward. Moreover, they observed that amphetamine produced the opposite effect, making it easier for rats to tolerate greater exertion of effort. Floresco et al. reported that haloperidol affected effort discounting even when one controlled for any 
possible time delays caused by completing the ratio [87]. Taken together, these results indicate that DA systems participate in the regulation of effort-based decision making.

\section{Forebrain circuits \& neurotransmitter interactions regulating effort-related processes}

Although interference with accumbens DA transmission can exert profound effects on some aspects of motivation, these effects do not appear to be a result of actions such as appetite suppression or reductions in the primary or unconditioned motivation for food $[8,11,15,49,77,89]$. Instead, considerable evidence indicates that DA antagonists and accumbens DA depletions alter functions such as behavioral activation, instrumental response output and allocation, and effort-related processes [8,11,14,15,49,77,87-92]. Of course, accumbens DA does not regulate effort-related processes in isolation, and for that reason it is important to review how other brain areas and neurotransmitters are involved. Several recent studies have shown that anterior cingulate cortex, basolateral amygdala and ventral pallidum also participate in effort-related processes [93-97]. The T-maze task previously described [73] has been employed to investigate the functions of frontal/cingulate cortical areas in addition to the accumbens. Walton et al. studied the effects of medial frontal cortex lesions that included prelimbic, infralimbic and anterior cingulate cortex, and demonstrated that these lesions shifted the behavior of the rats away from the arm that contained the high density of reinforcement that was obstructed by a barrier [94] . In a subsequent paper, lesions of the prelimbic and infralimbic cortex did not affect choice behavior, but lesions of the anterior cingulate cortex produced the same changes in effortrelated choice that had been shown previously with the larger lesions [95]. Large anterior cingulate catecholamine depletions were shown to affect T-maze choice behavior [96]. Furthermore, bilateral inactivation of anterior cingulate cortex also shifted choice behavior in the T-maze [97].

Recent research in this area has also focused on interactions between DA and the purine neuromodulator, adenosine. Four G-proteincoupled adenosine receptors have been identified, although the $A_{1}$ and $A_{2 A}$ subtypes predominate in the brain [98]. It has been known for some time that nonselective adenosine antagonists, such as caffeine and theophylline, act as minor stimulants [99]. Over the last two decades, there has been a tremendous growth in research on adenosine receptor neurochemistry and pharmacology, and the $A_{2 A}$ receptor subtype has received considerable attention. Both caudate/putamen (neostriatum) and nucleus accumbens are very rich in adenosine $A_{2 A}$ receptors [100-103]. There is a neurochemical interaction between striatal DA $D_{2}$ and adenosine $A_{2 A}$ receptors, which tend to be colocalized on the same enkephalin-positive medium spiny neurons [102-108]. The behavioral significance of this interaction has frequently been studied in the context of neostriatal motor functions and dysfunctions that are related to parkinsonism [104,105,109-116]. Investigators have also studied adenosine $A_{2 A}$ receptor pharmacology in relation to cognitive processes [117] and anxiety [118]. Within the last few years, the motivational significance of adenosine $A_{2 A}$ receptor pharmacology has become apparent, especially with regard to aspects of behavioral activation and effort-related processes [84,119-121].

Broadly speaking, injections of the adenosine $A_{2 \mathrm{~A}}$ agonist, CGS 21680, directly into nucleus accumbens have been shown to produce effects that resemble those of accumbens DA depletions or antagonism. Intra-accumbens injections of CGS 21680 reduced locomotor activity [122]. More recently, it was demonstrated that local injection of CGS 21680 into nucleus accumbens core reduced response on a VI $60 \mathrm{~s}$ schedule with an attached FR10 requirement attached, but did not impair performance on a standard VI 60 s schedule [121], an effect that has been shown to occur following accumbens DA depletions [68]. In rats responding to the operant FR5/chow feeding concurrent choice procedure, injections of CGS 21680 into the accumbens core decreased lever pressing and increased chow intake [120], a pattern of effects similar to that produced by accumbens DA depletions and antagonism. Injections of CGS 21680 into a control site dorsal to nucleus accumbens were ineffective [120].

Consistent with the observation that an adenosine $\mathrm{A}_{2 \mathrm{~A}}$ agonist could produce actions similar to those resulting from interference with DA transmission, it has also been demonstrated that adenosine $A_{2 \mathrm{~A}}$ receptor antagonists can reverse the effects of DA antagonists on effort-related choice behavior. Studies employing the T-maze barrier choice procedure demonstrated that the adenosine $\mathrm{A}_{2 \mathrm{~A}}$ receptor antagonist, MSX-3, could reverse the effects of the $\mathrm{D}_{2}$ antagonist haloperidol in both rats [75] and mice [76]. MSX-3 also reversed the effects of the $\mathrm{D}_{2}$ antagonists haloperidol and eticlopride in rats responding on the concurrent lever pressing/chow feeding procedure [79,84,119]. 
Similar effects have been produced by another adenosine $A_{2 A}$ receptor antagonist, istradefylline (KW 6002; [78, Nunes EJ, Randall Pa, Santerre JL et al., Unpublished Data]). These pharmacological studies indicate that there is a very specific interaction between $\mathrm{DA} \mathrm{D}_{2}$ and adenosine $\mathrm{A}_{2 \mathrm{~A}}$ receptor subtypes. Although the adenosine $\mathrm{A}_{2 \mathrm{~A}}$ receptor antagonist MSX-3 can reduce the effect of haloperidol in rats and mice responding on the T-maze task, the $A_{1}$ antagonists, 8-cyclopentyl-1,3-dipropylxanthine (DPCPX) and 8-cyclopentyltheophylline (CPT) were ineffective [75,76]. Similarly, DPCPX and CPT were unable to reverse the effects of haloperidol and eticlopride in rats responding on the operant concurrent choice task [78, Nunes EJ, Randall PA, Santerre Jl et al., Unpublished Data]. Despite the fact that both MSX-3 and istradefylline could reverse the effects of $\mathrm{D}_{2}$ antagonists, such as haloperidol and eticlopride, in rats responding on the operant concurrent choice procedure $[78,119,123]$,

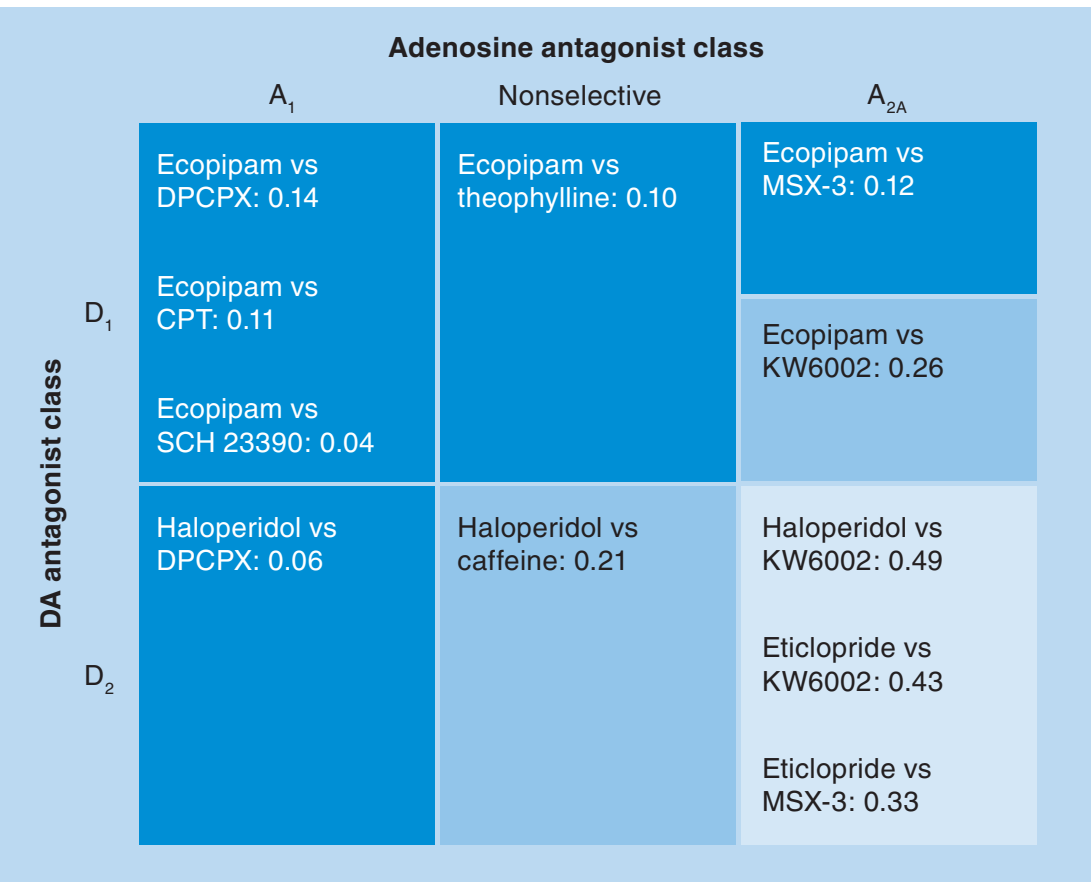

Figure 2. Summary of drug reversal studies with the operant concurrent choice task. This chart lists the effect sizes ( $R^{2}$ values) that provide a marker of the magnitude of the reversal effect of each adenosine antagonist when coadministered with a DA antagonist. These calculations were performed on the lever pressing data from published papers [78], as well as unpublished data [Nunes EJ, Randall PA, Santerre JL et al., Unpublished Data]. These analyses were conducted by removing the vehicle plus vehicle control data, and calculating the $\mathrm{R}^{2}$ value for the four treatments that included a DA antagonist injection alone as well as the DA antagonist combined with an adenosine antagonist. With this type of calculation, the magnitude of the treatment effect is independent of the number of animals, and is expressed as the proportion of total variance accounted for by treatment variance (e.g., $R^{2}=0.3$ reflects $30 \%$ of the variance explained across experiments and measures; larger effect sizes mean greater reversal effects).

CPT: 8-cyclopentyltheophylline; DA: Dopamine;

DCPCX: 8-cyclopentyl-1,3-dipropylxanthine. these drugs produced only a mild attenuation the effects of the $\mathrm{D}_{1}$ antagonists ecopipam ( $\mathrm{SCH}$ 39166) and SCH 23390 [123, Nunes EJ, Randall PA, Santerre Jl et al., Unpublished Data]. Furthermore, the adenosine $\mathrm{A}_{1}$ antagonists DPCPX and CPT were unable to reverse the effects of the DA $\mathrm{D}_{1}$ antagonist ecopipam [Nunes EJ, Randall PA, Santerre Jl et al., Unpublished Data]. Similar results were obtained with rats tested on a noveltyinduced locomotion procedure [124].

These findings indicate that there is a relatively selective interaction between antagonists of DA $\mathrm{D}_{2}$ and adenosine $\mathrm{A}_{2 \mathrm{~A}}$ receptors (Figure 2). Recently, it was demonstrated that either systemic or intra-accumbens injections of the adenosine $A_{2 A}$ receptor antagonist MSX-3 reversed the effects of intra-accumbens injections of the $\mathrm{D}_{2}$ antagonist eticlopride on effort-related choice [84], demonstrating that nucleus accumbens is an important locus for this $\mathrm{D}_{2}-\mathrm{A}_{2 \mathrm{~A}}$ interaction. Moreover, these results from studies of effort-related choice behavior are consistent with the large body of evidence demonstrating that $\mathrm{A}_{2 \mathrm{~A}}$ antagonism can generally reverse the effects of $\mathrm{D}_{2}$ antagonism across a wide range of behavioral contexts, including tasks that involve functions related to ventral and dorsal striatum $[115,116,124,125]$. The specificity of this interaction is possibly related to the pattern of cellular localization of adenosine $A_{1}$ and $A_{2 A}$ receptors in striatal areas, including the nucleus accumbens [103]. Adenosine $A_{2 A}$ receptors are located on enkephalin-positive striatal neurons that also express $\mathrm{DA}_{2}$ receptors $[98,100,103,106,126]$. DA $\mathrm{D}_{2}$ and adenosine $\mathrm{A}_{2 \mathrm{~A}}$ receptors are able to form heteromeric complexes, in which the two receptors become linked and display alterations in their binding characteristics, and these receptors also converge onto the same cAMP-related signal transduction pathways [103-105,107,108,127-129]. Thus, adenosine $A_{2 A}$ antagonists may be so effective at reversing the actions produced by $\mathrm{DA} \mathrm{D}_{2}$ antagonists because they reverse the basic cellular manifestations of $\mathrm{D}_{2}$ blockade. Consistent with this hypothesis, recent studies have employed c-Fos immunoreactivity to provide a cellular marker of the interaction between $\mathrm{DA}_{2}$ and adenosine $\mathrm{A}_{2 \mathrm{~A}}$ receptors. These experiments have demonstrated that doses of adenosine $\mathrm{A}_{2 \mathrm{~A}}$ antagonists that are effective at reversing the actions of $\mathrm{DA} \mathrm{D}_{2}$ antagonists on tremor and effort-related choice behavior can also reverse the $\mathrm{D}_{2}$-antagonist-induced enhancement of c-Fos expression in ventrolateral neostriatum [130] and nucleus accumbens core [84], respectively. However, despite the colocalization of $\mathrm{DA}_{1}$ and adenosine $\mathrm{A}_{1}$ receptors on 
the same striatal neurons [103], injections of the $\mathrm{A}_{1}$ antagonists DPCPX and CPT failed to reverse the behavioral effects of the DA $\mathrm{D}_{1}$ antagonist ecopipam [Nunes EJ, Randall Pa, Santerre Jl et al., Unpublished Data].

In summary, research over the last few years has begun to identify components of the brain circuitry involved in effort-related processes. Nucleus accumbens DA and adenosine interact to regulate effort-related choice behavior, and other structures, such as basolateral amygdala and prefrontal/anterior cingulate cortex, are also involved. Figure 3 provides an outline of the forebrain circuits that participate in effort-related functions. Recent research employing a combination of behavioral, anatomical, neurochemical and pharmacological methods has contributed to our understanding of the interactions that occur between different components of this circuitry. Using 'disconnection' methods, Floresco and Ghods-Sharifi demonstrated that unilateral inactivation of the basolateral amygdala on one side of the brain, combined with contralateral inactivation of the anterior cingulate cortex, substantially altered performance on the T-maze barrier choice task [97]. These findings support the hypothesis that serial transfer of information between these structures is involved in effortrelated decision making. A similar conclusion was reached by Hauber and Sommer [131], who reported that unilateral cell body lesions of anterior cingulate cortex combined with contralateral cell body lesions of nucleus accumbens can also change effort-based decision making in rats responding on the T-maze task. Another part of this circuitry appears to be the ventral striatopallidal pathway. Neurons originating in nucleus accumbens core areas that have been implicated in effort-related processes project to the lateral ventral pallidum $[121,132]$. The cell bodies of many of these neurons also contain adenosine $A_{2 A}$ receptors [121]. This projection is GABAergic, and recent evidence indicates that extracellular levels of GABA, as measured by microdialysis, were increased by local accumbens core injections of either the adenosine $A_{2 A}$ agonist CGS 21680 [121] or the $\mathrm{DA} \mathrm{D}_{2}$ antagonist eticlopride (Figure 4) at doses that also produce the shift from lever pressing to chow intake in rats responding on the operant concurrent choice task. Consistent with this observation, it was reported that injections of the $\mathrm{GABA}_{\mathrm{A}}$ agonist, muscimol, directly into the ventral pallidum also decreased lever pressing and increased chow intake [132], while injections of muscimol into a control site dorsal to the ventral pallidum were ineffective. Moreover, injections

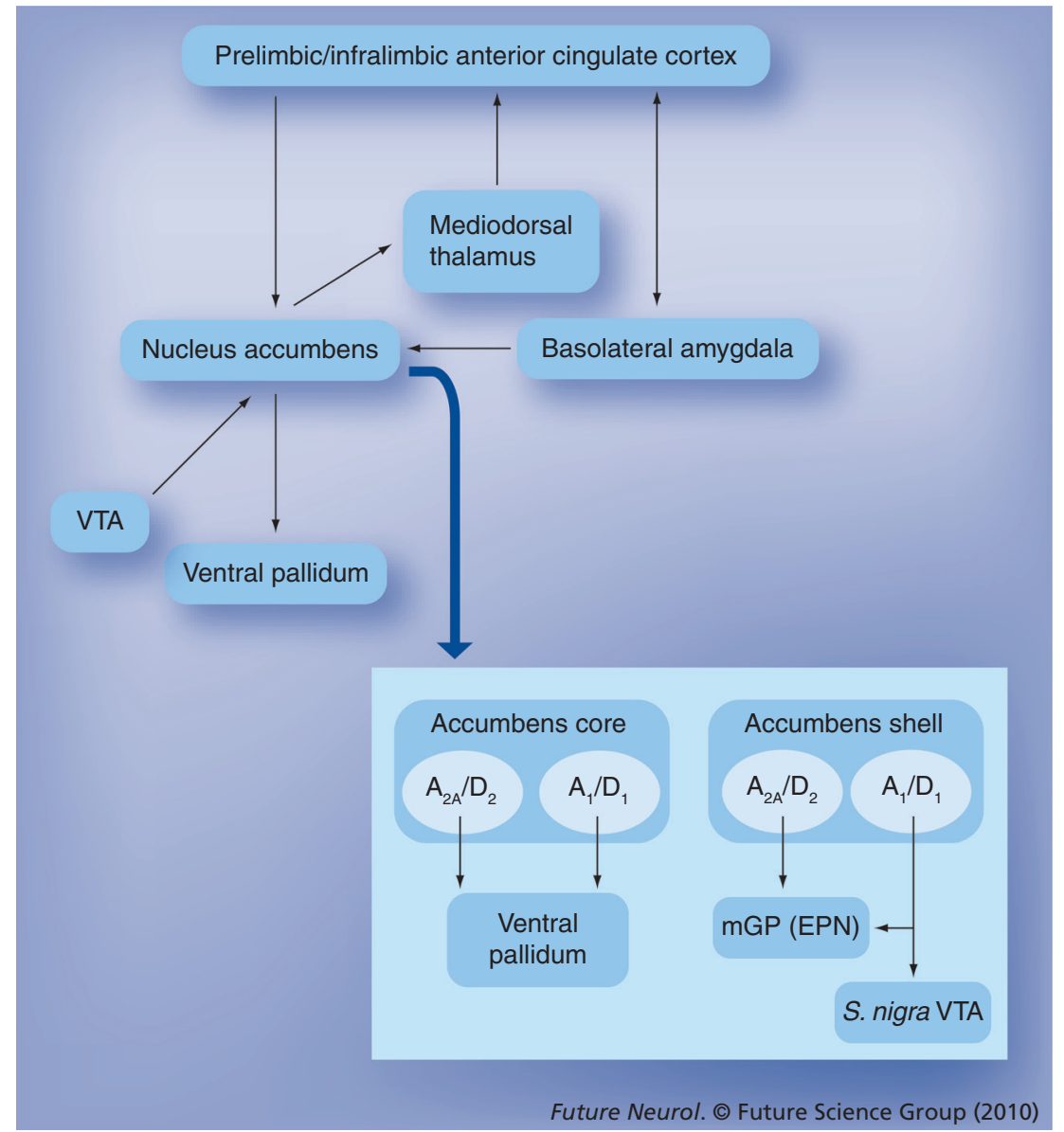

Figure 3. Forebrain circuits involved in effort-related functions.

Top: Anatomical circuit diagram showing the connections between nucleus accumbens and other brain interconnected brain areas (frontal/cingulated cortex, amygdala and pallidal areas) that are involved in the regulation of behavioral activation and effort-related decision making. Lower right (see arrow): enhanced view of nucleus accumbens showing localization patterns for dopamine and adenosine receptors.

EPN: Entopeduncular nucleus; mGP: Medial globus pallidus; S. nigra: Substantia nigra; VTA: Ventral tegmental area.

of the adenosine $A_{2 A}$ agonist CGS 21680 into nucleus accumbens on one side of the brain, combined with muscimol injected into the ventral pallidum on the contralateral side, reduced lever pressing in rats responding on a VI 60 s schedule that had an additional work requirement (FR10) attached [121]. This effect is very similar to that previously reported to occur after accumbens DA depletions [68].

\section{Clinical significance}

In addition to contributing to the basic scientific understanding of brain mechanisms related to aspects of motivation, studies of effort-related processes also have substantial clinical implications. In her book Manic, Cheney describes her own subjective experience of mania in the following terms: "increased energy: during 

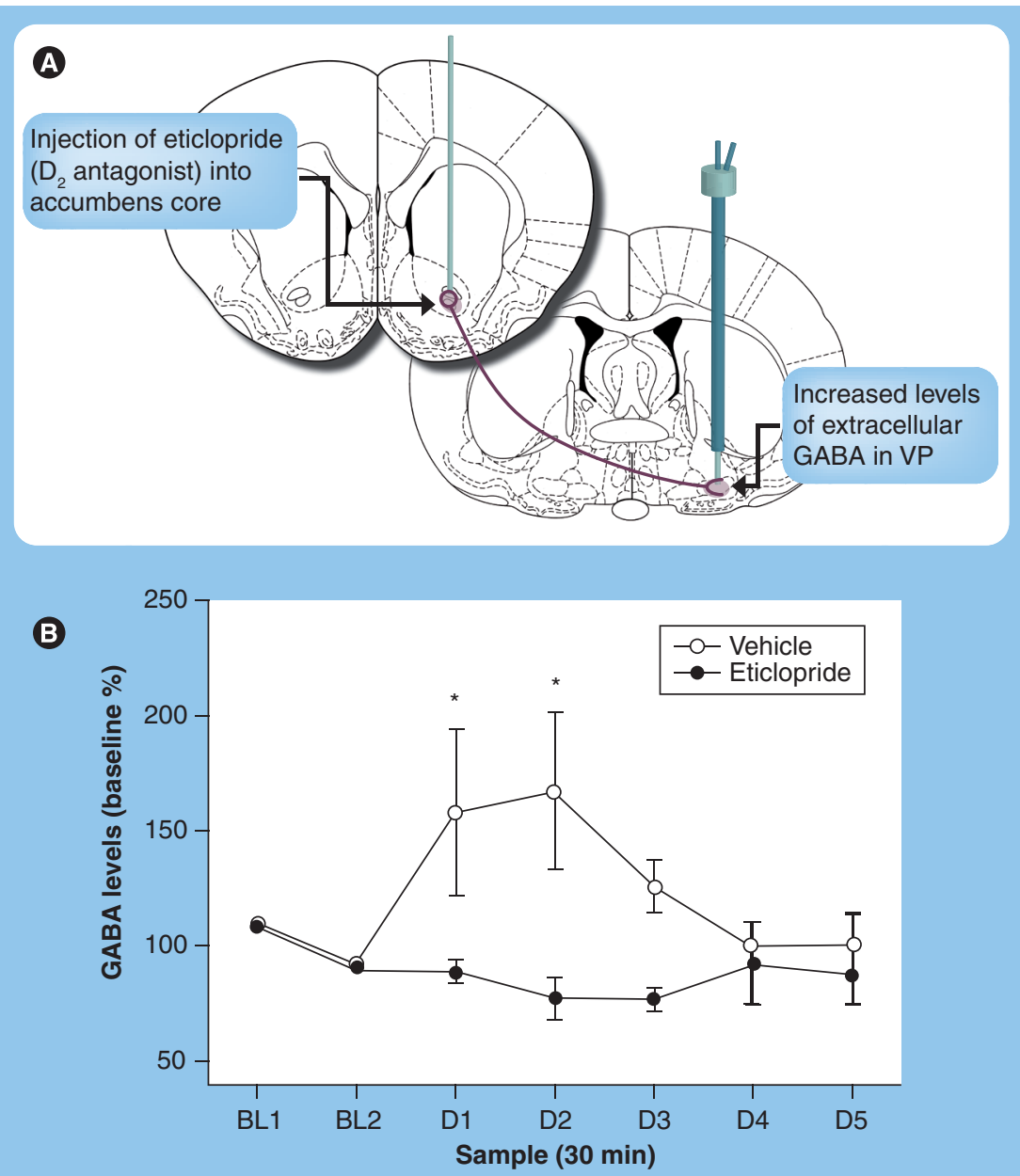

Figure 4. $D$ blockade in nucleus accumbens increases GABA release in ventral pallidum. (A) Diagram showing the placement of a drug injection cannula in nucleus accumbens, and a microdialysis probe in the ipsilateral ventral pallidum. For these studies [FARRAR, UNPUBLISHED DOCTORAL DISSERTATION, UNIVERSITY OF Connecticut, 2009], either $4.0 \mu \mathrm{g}$ of the $D_{2}$ antagonist eticlopride $(n=7)$ or saline vehicle $(n=8)$ was injected into the nucleus accumbens core $(1.0 \mu \mathrm{l}$ total volume). The dialysis samples obtained from ventral pallidum were collected over successive 30-min periods and were analyzed using high-performance liquid chromatography with electrochemical detection. These microdialysis and neurochemical methods have been published previously [124]. Rat brain coronal sections were modified from [133]. (B) Graph showing the effect of eticlopride injection on extracellular GABA, with data expressed as a percentage of baseline. This graph includes data (mean + standard error of the mean) from the last two baseline preinjection samples (BL1-2), and the five samples after injection, for groups treated with eticlopride or vehicle (D1-5; the arrow in (A) indicates point of injection). Analysis of variance revealed that there were no group differences in the raw GABA levels of the baseline samples $(F[1,13]=0.014$; not significant), nor was there a difference between the first and second baseline samples ( $F[1,13]=4.42$; not significant) Infusion of eticlopride into accumbens core significantly increased levels of extracellular GABA in ventral pallidum. Analysis of variance revealed a significant effect of drug treatment $(F[1,13]=8.02 ; p<0.05)$ and a significant treatment by sample interaction $(F[6,78]=3.54 ; p<0.05)$. Non-orthogonal planned comparisons revealed that the eticlopride-treated group had significantly elevated VP GABA levels at the first and second postinjection samples $\left({ }^{*} p<0.05\right)$.

Furthermore, orthogonal analysis of trends across all seven samples for the percentage baseline data demonstrated a significant sample $X$ treatment interaction for the quadratic trend $(F[1,13]=7.20 ; p<0.05)$, indicating that ventral pallidal GABA levels in the eticlopride-treated group showed an increase followed by a decrease, whereas GABA levels for the vehicle group did not. VP: Ventral pallidum. manic episodes, I can zip through all the work I couldn't touch while I was depressed" [133]. Although depression is defined as an affective disorder, with symptoms that include mood alterations and negative affect, some of the most common symptoms of depression are energy-related dysfunctions such as slowness, tiredness, listlessness and apathy [134,135]. Sometimes referred to as psychomotor slowing or retardation, anergia or fatigue, this cluster of symptoms can be a debilitating feature of major depressive disorder, and can also be present in other psychiatric and neurological conditions [134-157].

The neural basis of the impaired psychomotor function presented in major depressive disorder is still being characterized. Nevertheless, considerable evidence implicates central DA, basal ganglia and cortical mechanisms [11,140-145]. Caligiuri and Ellwanger suggested that DA transmission could play an important role in the expression of psychomotor slowing in depression [142]. Schmidt et al. observed that reduced DA transmission in psychiatric patients was not related to anhedonia, but instead was related to decreased interaction with the environment and psychomotor slowing [144]. The efficacy of several antidepressant drugs for reversing psychomotor slowing in depressed patients was related to the ability of these drugs to inhibit DA uptake [145]. Stimulants that enhance DA transmission have also been used to treat energy-related symptoms in depressed individuals [136]. Antiparkinsonian drugs such as L-DOPA and bromocriptine have mixed antidepressant characteristics with regard to other symptoms of depression, but they do tend to improve anergia [141]. Imaging studies also have implicated the basal ganglia structures, as well as interconnected brain areas such as prefrontal cortex and anterior cingulate cortex, in psychomotor slowing in depression [146,147].

In addition to being a feature of major depressive disorder, energy-related dysfunctions are often observed in patients with other psychiatric or neurological conditions. Moreover, as is the case with major depression, the anergia, apathy and fatigue observed in these patients appears to involve DA systems and basal ganglia mechanisms. There are several reports of energy-related problems, typically labeled fatigue, in patients with Parkinson's disease [152]. These patients describe their loss of energy by statements such as "my energy bubble just bursts" and "it's like my battery runs down" [152]. Caligiuri and Ellwanger compared 
motor function in depressed patients and those with parkinsonism [142], and observed that motor slowing in depression is behaviorally quite similar to parkinsonian bradykinesia. They suggested that motor slowing in depression and parkinsonism could result from common underlying mechanisms. Psychomotor slowing is often observed during withdrawal from stimulant addiction, and it was the psychiatric symptom most strongly associated with reduced levels of striatal DA transporter density in a PET study of methamphetamine abusers in withdrawal [143]. Furthermore, there are individuals who have a severe motivational disturbance that has been labeled as anergia, or apathy, yet these individuals do not meet the diagnostic criteria for depression [148,149]. Energy-related symptoms in these people can be ameliorated with the DA agonist bromocriptine, and it has been suggested that DA is involved in this type of syndrome [148,149]. The DA uptake inhibitor buproprion improved apathy symptoms in patients with organic brain disease [150]. Loss of drive or motivation and a lack of initiation of spontaneous activities was reported to be improved by administration of the antiparkinsonian DA agonist bromocriptine in patients who had either traumatic brain injury or subarachnoid hemorrhage [151]. Another disorder associated with energy-related symptoms such as fatigue is multiple sclerosis [152,153]. Fatigue in multiple sclerosis has been described as "a feeling of physical tiredness and lack of energy distinct from sadness or weakness" [154]. Basal ganglia mechanisms have been implicated in multiple sclerosis-related fatigue [155], and drugs that act on DA such as pemoline and buproprion have been used to treat this symptom $[153,156]$. Furthermore, HIV patients can also show apathy, and a recent morphometric study demonstrated that this apathy in HIV patients is accompanied by reductions in nucleus accumbens volume [157].

It is evident from the review of the animal research provided above that adenosine $A_{2 A}$ receptor antagonists could represent novel therapeutic targets for the treatment of energyrelated symptoms in humans. At present, a number of these drugs are being developed as treatments for idiopathic Parkinson's disease. As fatigue is often a feature of Parkinson's disease [152], the next generation of studies could provide a unique opportunity to investigate the ability of adenosine $A_{2 A}$ antagonists to improve energy-related symptoms. Additional research should also focus on the effects of adenosine
$A_{2 A}$ antagonists on psychomotor slowing and fatigue in patients treated with antipsychotic drugs, as well as people with multiple sclerosis, depression or other disorders. For all these studies, it will be useful to place emphasis on the continued development of both self-report and behavioral assessment tools, in order to characterize the symptoms and measure their responsiveness to treatment.

\section{Conclusion}

In summary, there are multiple components of the forebrain circuitry regulating behavioral activation and effort-related processes. One nodal point in this circuitry is the DA innervation of nucleus accumbens $[11,13,77,85,158]$. Low systemic doses of DA antagonists, local injections of DA antagonists into nucleus accumbens and neurotoxic depletion of accumbens DA, all produce a condition that results in lower behavioral activation and decreased output of food-motivated instrumental behavior, particularly when the instrumental response has a substantial work requirement. These actions occur despite the fact that these manipulations have little or no effect on appetite for food, or primary or unconditioned food motivation [13]. In addition, DA manipulations produce a bidirectional modulation of effortrelated choice behavior. Decreasing accumbens DA transmission biases animals towards lower-effort alternatives, although these animals remain directed towards the acquisition and consumption of the primary motivational stimulus $[11,13,158]$. By contrast, increasing DA transmission has been demonstrated to increase selection of high-effort alternatives [79,87]. Along with nucleus accumbens, additional components of this circuitry in animals and humans include prefrontal/anterior cingulate cortex, basolateral amygdala and ventral pallidum [93,131,159-161]. Furthermore, DA interacts with the purine neuromodulator adenosine, particularly in the nucleus accumbens, to regulate effort-related functions $[13,77,85,158]$. Adenosine $\mathrm{A}_{2 \mathrm{~A}}$ agonists injected into nucleus accumbens can mimic the effects of DA depletion or antagonism, while adenosine $A_{2 A}$ antagonists can attenuate the effort-related behavioral effects of $\mathrm{DA} \mathrm{D}_{2}$ antagonists.

As well as providing basic science information regarding a fundamental aspect of normal motivation, research in this area can also yield insights into pathological aspects of motivation in humans [134]. Symptoms such as anergia, psychomotor slowing, apathy and fatigue, which 
represent conditions in which there are abnormally low levels of behavioral activation, are frequently observed in patients with depression and other psychiatric and neurological disorders. Subjectively, patients with these symptoms report a lack of energy, and research indicates that there are also profound behavioral manifestations that can be maladaptive and debilitating. The severity of these psychomotor or energy-related symptoms is related to problems with social function and employment, as well as treatment outcomes [162]. Importantly, an examination of the basic science and clinical literature indicates that there are noteworthy similarities between the brain circuitry and neurochemical systems that have been implicated in effort-related processes in animals and those involved in pathological aspects of behavioral activation in humans [11,134]. These observations suggest that basic research on animals can yield critical insights into the neural underpinnings of energy-related dysfunctions in humans, and that such research could ultimately lead to novel treatments for these disorders. For example, it is possible that adenosine $\mathrm{A}_{2 \mathrm{~A}}$ receptor antagonists that are currently being developed for their antiparkinsonian effects could be beneficial for treating energy-related symptoms in humans $[11,119,163]$.

\section{Future perspective}

As previously described, in most animal studies adenosine $A_{2 A}$ receptor antagonists appear to be more effective at reversing the effects of $\mathrm{D}_{2}$ antagonists than they are at reversing the effects of $\mathrm{D}_{1}$ antagonists. This will have to be investigated more thoroughly in humans, but it could have implications for the development of these compounds as clinical tools. As DA depletions result in a lack of $\mathrm{D}_{1}$ as well as $\mathrm{D}_{2}$ receptor stimulation, it may be that adenosine $\mathrm{A}_{2 \mathrm{~A}}$ antagonists will have limited efficacy in treating patients with idiopathic Parkinson's disease. As previously described, adenosine $A_{2 \mathrm{~A}}$ receptor antagonists appear to have more direct effects on the medium spiny cells that also contain $\mathrm{D}_{2}$ receptors, but their ability to interact with so-called direct pathway neurons, which are more likely to contain $\mathrm{D}_{1}$ receptors, may be somewhat limited. For these reasons, it would be useful to consider combination treatments that include drugs that act on other parts of the striatal circuitry, which are less influenced by the effect of adenosine $A_{2 A}$ receptor blockade; such treatments could include $\mathrm{D}_{1}$ agonists or muscarinic M4 antagonists [131]. This strategy could yield benefits for the treatment of motor symptoms of Parkinson's disease, but could also be advantageous for the treatment of energy-related symptoms as well.

\section{Executive summary}

\section{Diverse aspects of motivation}

- Directional aspects: behavior is directed towards or away from stimuli.

- Activational aspects: motivated behavior is characterized by a high degree of vigor, persistence and effort.

\section{Dopaminergic involvement in behavioral activation \& effort}

- Low doses of dopamine (DA) antagonists, as well as accumbens DA depletions or antagonism, do not impair appetite for food or primary food motivation. It is overly simplistic to label nucleus accumbens DA as a 'reward' or 'pleasure' system.

- Interference with DA transmission impairs activational aspects of motivation, making it less likely that animals will work for stimuli such as food.

- Interference with accumbens DA transmission affects effort-related decision making, biasing animals towards low-effort alternatives.

\section{Dopamine \& adenosine interact in the regulation of effort-related processes}

- Adenosine $A_{2 A}$ agonists, when injected into the accumbens, produce effects that resemble those of accumbens DA depletion or antagonism.

- Adenosine $A_{2 A}$ antagonists reverse the effort-related effects of $D A$ antagonists, while $A_{1}$ antagonists are relatively ineffective.

- There is a very specific interaction between $D A D_{2}$ and adenosine $A_{2 A}$ receptors, which is probably related to the colocalization of these receptors in the same population of medium spiny neurons.

- The nucleus accumbens is an important locus at which DA $D_{2}$ and adenosine $A_{2 A}$ receptors interact in order to regulate effort-related processes.

- Effort-related output from the nucleus accumbens to related forebrain circuits appears to be conveyed by the GABAergic ventral striatopallidal pathway.

- The broader forebrain circuitry involved in effort-related processes includes the anterior cingulate cortex and basolateral amygdala.

\section{Clinical implications}

- Animal research on behavioral activation and effort-related decision making may provide insights into the neurochemistry and pharmacology of effort- or energy-related symptoms, such as psychomotor slowing, anergia, apathy and fatigue, which are seen in various psychiatric and neurological disorders.

\section{Future perspective}

- - Adenosine $A_{2 A}$ receptor antagonists may be useful for the treatment of energy-related symptoms in humans 
In view of the apparent specificity of the interaction between $\mathrm{DA} \mathrm{D}_{2}$ and adenosine $\mathrm{A}_{2 \mathrm{~A}}$ receptors, another potential use for adenosine $\mathrm{A}_{2 \mathrm{~A}}$ antagonists is the treatment of the behavioral side effects, both motor and motivational, that are produced by antipsychotic drugs $[115,116,119]$. The vast majority of antipsychotic drugs are $\mathrm{D}_{2}$ antagonists, and the therapeutic utility of these compounds is directly related to actions on the $\mathrm{D}_{2}$ receptor family, as opposed to the $\mathrm{D}_{1}$ receptor family. Thus, in view of the consistent findings in the animal literature that demonstrates that adenosine $A_{2 A}$ antagonists readily reverse the actions of $\mathrm{D}_{2}$ antagonists, clinical studies assessing this effect need to be conducted. Of course, in order to be clinically useful, the question of whether or not adenosine $A_{2 \mathrm{~A}}$ antagonists also reverse the therapeutic effect of antipsychotics needs to be addressed. Such research would not only be necessary from a practical standpoint, but it would also have an added benefit, in that it would test one of the recent theories of antipsychotic action. Although many researchers have maintained that the therapeutic and behavioral side effects of antipsychotic drugs result from actions on distinct mechanisms, it has recently been suggested that the therapeutic effect of $D_{2}$ antagonists is a result of actions on subcortical dopaminergic mechanisms, including those in nucleus accumbens, which are involved in aspects of motivation such as motivational salience and arousal [164]. Thus, research in this area could afford a valuable opportunity that would have both clinical and theoretical implications. If adenosine $A_{2 A}$ antagonists can reverse the motivational effects of $\mathrm{D}_{2}$ antagonists, but leave the therapeutic antipsychotic effect intact, then it would indicate that these effects are actually a result of actions on distinct and dissociable mechanisms. Moreover, such a finding would promote the development of novel clinical tools for the treatment of pathological aspects of motivation.

\section{Financial \& competing interests disclosure \\ This work was supported by grants to John D Salamone from the National Institute of Mental Health (MH078023) and from Lundbeck (Copenhagen, Denmark), and by a grant to Merce Correa from Conselleria de Empresa, Universitat $i$ Ciència, Generalitat Valenciana, (BEST2008/027), Spain. For some studies reviewed in this article, KW6002 was generously supplied by Lundbeck (Copenhagen, Denmark). The authors have no other relevant affiliations or financial involvement with any organization or entity with a financial interest in or financial conflict with the subject matter or materials discussed in the manuscript apart from those disclosed. \\ No writing assistance was utilized in the production of this manuscript.}

\section{Bibliography}

Papers of special note have been highlighted as:

- of interest

-" of considerable interest

1. Salamone JD: Motor function and motivation. In: Encyclopedia of Behavioral Neuroscience. Koob G, Le Moal M, Thompson RF (Eds). Elsevier, Oxford, UK (2010) (In Press).

2. Salamone JD: Behavioral pharmacology of dopamine systems: a new synthesis. In: The Mesolimbic Dopamine System: From Motivation to Action. Willner P, Scheel-Kruger J (Eds). Cambridge University Press, Cambridge, UK, 599-613 (1991).

3. Salamone JD: Complex motor and sensorimotor functions of striatal and accumbens dopamine: involvement in instrumental behavior processes. Psychopharmacology 107, 160-174 (1992).

4. Salamone JD, Correa M: Motivational views of reinforcement: implications for understanding the behavioral functions of nucleus accumbens dopamine. Behav. Brain Res. 137, 3-25 (2002).
5. Cofer CN, Appley MH: Motivation: Theory and Research. John Wiley and Sons, NY, USA (1964).

6. Duffy E: Activation and Behavior. John Wiley and Sons, NY, USA (1963).

7. Salamone JD: Dopaminergic involvement in activational aspects of motivation: effects of haloperidol on schedule induced activity, feeding and foraging in rats. Psychobiology 16, 196-206 (1988).

8. Salamone JD, Cousins MS, Snyder BJ: Behavioral functions of nucleus accumbens dopamine: empirical and conceptual problems with the anhedonia hypothesis. Neurosci. Biobehav. Rev. 21, 341-359 (1997).

9. Salamone JD, Correa M, Mingote S, Weber SM: Nucleus accumbens dopamine and the regulation of effort in food-seeking behavior: implications for studies of natural motivation, psychiatry, and drug abuse. J. Pharmacol. Exp. Ther. 305, 1-8 (2003).

10. Salamone JD, Correa M, Mingote SM, Weber SM: Beyond the reward hypothesis: alternative functions of nucleus accumbens dopamine. Curr. Opin. Pharmacol. 5, 34-41 (2005).
11. Salamone JD, Correa M, Farrar A, Mingote SM: Effort-related functions of nucleus accumbens dopamine and associated forebrain circuits. Psychopharmacology 191, 461-482 (2007).

- Exhaustive review of the role of dopamine in effort-related processes that provides a thorough discussion of the problems with the dopamine hypothesis of 'reward'.

12. van den Bos R, van der Harst J, Jonkman S, Schilders M, Spruijt B: Rats assess costs and benefits according to an internal standard. Behav. Brain Res. 171, 350-354 (2006).

13. Salamone JD, Correa M: Dopamine/ adenosine interactions involved in effortrelated aspects of food motivation. Appetite 53, 422-425 (2009).

14. Barbano MF, Cador M: Opioids for hedonic experience and dopamine to get ready for it. Psychopharmacology 191, 497-506 (2007).

15. Kelley AE, Baldo BA, Pratt WE, Will MJ: Corticostriatal-hypothalamic circuitry and food motivation: integration of energy, action and reward. Physiol. Behav. 86, 773-795 (2005). 
16. Salamone JD: Functions of mesolimbic dopamine: changing concepts and shifting paradigms. Psychopharmacology 191, 389 (2007).

17. Treit D, Berridge KC: A comparison of benzodiazepine, serotonin, and dopamine agents in the taste-reactivity paradigm. Pharmacol. Biochem. Behav. 37, 451-456 (1990).

18. Berridge KC, Robinson TE: What is the role of dopamine in reward: hedonic impact, reward learning, or incentive salience? Brain Res. Brain Res. Rev. 28, 309-369 (1998).

19. Berridge KC: The debate over dopamine's role in reward: the case for incentive salience. Psychopharmacology 191, 391-431 (2007).

- Comprehensive review of the role of dopamine in incentive salience processes that outlines the argument that dopamine does not mediate hedonic functions. This article provides excellent conceptual and empirical background for dopaminergic involvement in 'wanting' as opposed to 'liking'.

20. Berridge KC, Kringlebach ML: Affective neuroscience of pleasure: reward in humans and animals. Psychopharmacology 199 , 457-480 (2008).

21. Gunne LM, Anggard E, Jonsson LE: Clinical trials with amphetamine-blocking drugs. Psychiatr. Neurol. Neurochir. 75, 225-226 (1972).

22. Gawin FH: Neuroleptic reduction of cocaine-induced paranoia but not euphoria? Psychopharmacology 90, 142-143 (1986).

23. Brauer LH, De Wit H: High dose pimozide does not block amphetamine-induced euphoria in normal volunteers. Pharmacol. Biochem. Behav. 56, 265-272 (1997).

24. Wachtel SR, Ortengren A, de Wit H: The effects of acute haloperidol or risperidone on subjective responses to methamphetamine in healthy volunteers. Drug Alcohol Depend. 68, 23-33 (2002).

25. Nann-Vernotica E, Donny EC, Bigelow GE, Walsh SL: Repeated administration of the $\mathrm{D}_{1 / 5}$ antagonist ecopipam fails to attenuate the subjective effects of cocaine. Psychopharmacology 155, 338-347 (2001).

26. Haney M, Ward AS, Foltin RW, Fischman MW: Effects of ecopipam, a selective dopamine $\mathrm{D}_{1}$ antagonist, on smoked cocaine self-administration by humans. Psychopharmacology 155, 330-337 (2001).

27. Leyton M, Casey KF, Delaney JS, Kolivakis T, Benkelfat C: Cocaine craving, euphoria, and self-administration: a preliminary study of the effect of catecholamine precursor depletion. Behav. Neurosci. 119, 1619-1627 (2005).
28. McCullough LD, Salamone JD: Anxiogenic drugs $\beta$-CCE and FG 7142 increase extracellular dopamine levels in nucleus accumbens. Psychopharmacology 109, 379-382 (1992).

29. McCullough LD, Sokolowski JD, Salamone JD: A neurochemical and behavioral investigation of the involvement of nucleus accumbens dopamine in instrumental avoidance. Neuroscience 52, 919-925 (1993).

30. Salamone JD: The involvement of nucleus accumbens dopamine in appetitive and aversive motivation. Behav. Brain Res. 61, 117-133 (1994).

31. Schoenbaum G, Setlow B: Lesions of nucleus accumbens disrupt learning about aversive outcomes. J. Neurosci. 23, 9833-9841 (2003).

32. Salamone JD: The behavioral neurochemistry of motivation: methodological and conceptual issues in studies of the dynamic activity of nucleus accumbens dopamine. J. Neurosci. Methods 64, 137-149 (1996).

33. Levita L, Hare TA, Voss HU et al:: The bivalent side of the nucleus accumbens. Neuroimage 44, 1178-1187 (2009).

34. Liberzon I, Taylor SF, Amdur R et al.: Brain activation in PTSD in response to traumarelated stimuli. Biol. Psychiatry 45, 817-826 (1999).

35. Marinelli S, Pascucci T, Bernardi G, Puglisi-Allegra S, Mercuri NB: Activation of TRPV1 in the VTA excites dopaminergic neurons and increases chemical- and noxious-induced dopamine release in the nucleus accumbens.

Neuropsychopharmacology 30, 864-875 (2005).

36. Pavic L: Alterations in brain activation in posttraumatic stress disorder patients with severe hyperarousal symptoms and impulsive aggressiveness. Eur. Arch. Psychiat. Clin. Neurosci. 253, 80-83 (2003).

37. Jensen J, McIntosh AR, Crawley AP, Mikulis DJ, Remington G, Kapur S: Direct activation of the ventral striatum in anticipation of aversive stimuli. Neuron 40 , 1251-1257 (2003).

38. Pezze MA, Feldon J: Mesolimbic dopaminergic pathways in fear conditioning. Prog. Neurobiol. 74, 301-320 (2004).

39. Phan KL, Taylor SF, Welsh RC, Ho SH, Britton JC, Liberzon I: Neural correlates of individual ratings of emotional salience: a trial-related fMRI study. Neuroimage 21, 768-780 (2004).
40. Pruessner JC, Champagne F, Meaney MJ, Dagher A: Dopamine release in response to a psychological stress in humans and its relationship to early life maternal care: a positron emission tomography study using ${ }^{11} \mathrm{C}$ raclopride. J. Neurosci. 24, 2825-2831 (2004).

41. Anstrom KK, Woodward DJ: Restraint increases dopaminergic burst firing in awake rats. Neuropsychopharmacology 30, 1832-1840 (2005).

42. Delgado MR, Li J, Schiller D, Phelps EA: The role of the striatum in aversive learning and aversive prediction errors. Philosophical Transactions of the Royal Society 363 , 3787-3800 (2008).

- Excellent summary of the literature that presents stimulating findings related to the involvement of striatal mechanisms in aversive learning and motivation.

43. Faure A, Reynolds SM, Richard JM, Berridge KC: Mesolimbic dopamine in desire and dread: enabling motivation to be generated by localized glutamate disruptions in nucleus accumbens. J. Neurosci. 28, 7184-7192 (2008).

44. Brischoux F, Chakraborty S, Brierley DI, Ungless MA: Phasic excitation of dopamine neurons in ventral VTA by noxious stimuli. Proc. Natl Acad. Sci. USA 106, 4894-4899 (2009).

45. Dunnett SB, Iversen SD: Regulatory impairments following selective 6-OHDA lesions of the neostriatum. Behav. Brain Res. 4, 195-202 (1982).

46. Salamone JD, Mahan K, Rogers S: Ventrolateral striatal dopamine depletions impair feeding and food handling in rats. Pharmacol. Biochem. Behav. 44, 605-610 (1993).

47. Ungerstedt U: Adipsia and aphagia after 6-hydroxydopamine induced degeneration of the nigro-striatal dopamine system. Acta Physiol. Scand. Suppl. 367, 95-122 (1971).

48. Koob GF, Riley SJ, Smith SC, Robbins TW: Effects of 6-hydroxydopamine lesions of the nucleus accumbens septi and olfactory tubercle on feeding, locomotor activity, and amphetamine anorexia in the rat. J. Comp. Physiol. Psychol. 92, 917-927 (1978).

49. Baldo BA, Sadeghian K, Basso AM, Kelley AE: Effects of selective dopamine $\mathrm{D}_{1}$ or $\mathrm{D}_{2}$ receptor blockade within nucleus accumbens subregions on ingestive behavior and associated motor activity. Behav. Brain Res. 137, 165-177 (2002).

50. Salamone JD, Zigmond MJ, Stricker EM: Characterization of the impaired feeding behavior in rats given haloperidol or dopamine-depleting brain lesions. Neuroscience 39, 17-24 (1990). 
51. Salamone JD, Steinpreis RE, McCullough LD, Smith P, Grebel D, Mahan K: Haloperidol and nucleus accumbens dopamine depletion suppress lever pressing for food but increase free food consumption in a novel food choice procedure. Psychopharmacology 104, 515-521 (1991).

52. Aberman JE, Salamone JD: Nucleus accumbens dopamine depletions make rats more sensitive to high ratio requirements but do not impair primary food reinforcement. Neuroscience $92,545-552$ (1999).

53. Salamone JD, Arizzi M, Sandoval MD, Cervone KM, Aberman JE: Dopamine antagonists alter response allocation but do not suppress appetite for food in rats: contrast between the effects of SKF 83566, raclopride and fenfluramine on a concurrent choice task. Psychopharmacology 160, 371-380 (2002).

54. Sink KS, Vemuri VK, Olszewska T, Makriyannis A, Salamone JD: Cannabinoid $\mathrm{CB} 1$ antagonists and dopamine antagonists produce different effects on a task involving response allocation and effort-related choice in food-seeking behavior. Psychopharmacology 196, 565-574 (2008).

55. Hull EM, Weber MS, Eaton RC et al.: Dopamine receptors in the ventral tegmental area affect motor, but not motivational or reflexive, components of copulation in male rats. Brain Res. 554, 72-76 (1991).

56. Paredes RG, Agmo A: Has dopamine a physiological role in the control of sexual behavior? A critical review of the evidence. Prog. Neurobiol. 73, 179-226 (2004).

57. Pereira M, Uriarte N, Agrati D, Zuluaga MJ, Ferreira A: Motivational aspects of maternal anxiolysis in lactating rats. Psychopharmacology 180, 241-248 (2005).

58. Numan M, Numan MJ, Pliakou $\mathrm{N}$ et al.: The effects of $\mathrm{D}_{1}$ or $\mathrm{D}_{2}$ dopamine receptor antagonism in the medial preoptic area, ventral pallidum, or nucleus accumbens on the maternal retrieval response and other aspects of maternal behavior in rats. Behav. Neurosci. 119, 1588-1604 (2005).

59. Correa M, Carlson BB, Wisniecki A, Salamone JD: Nucleus accumbens dopamine and work requirements on interval schedules. Behav. Brain Res. 137, 179-187 (2002).

60. Cousins MS, Sokolowski JD, Salamone JD: Different effects of nucleus accumbens and ventrolateral striatal dopamine depletions on instrumental response selection in the rat. Pharmacol. Biochem. Behav. 46, 953-951 (1993).
61. Robbins TW, Koob GF: Selective disruption of displacement behaviour by lesions of the mesolimbic dopamine system. Nature 285, 409-412 (1980).

62. Wallace M, Singer G, Finlay J, Gibson S: The effect of 6-OHDA lesions of the nucleus accumbens septum on schedule-induced drinking, wheelrunning and corticosterone levels in the rat. Pharmacol. Biochem. Behav. 18, 129-136 (1983).

63. McCullough LD, Salamone JD: Involvement of nucleus accumbens dopamine in the motor activity induced by periodic food presentation: a microdialysis and behavioral study. Brain Res. 592, 29-36 (1992).

64. McCullough LD, Cousins MS, Salamone JD: The role of nucleus accumbens dopamine in responding on a continuous reinforcement operant schedule: a neurochemical and behavioral study. Pharmacol. Biochem. Behav. 46, 581-586 (1993).

65. Salamone JD, Kurth P, McCullough LD, Sokolowski JD: The effects of nucleus accumbens dopamine depletions on continuously reinforced operant responding: contrasts with the effects of extinction. Pharmacol. Biochem. Behav. 50, 437-443 (1995).

66. Sokolowski JD, Salamone JD: The role of accumbens dopamine in lever pressing and response allocation: effects of 6-OHDA injected into core and dorsomedial shell. Pharmacol. Biochem. Behav. 59, 557-566 (1998).

67. Ishiwari K, Weber SM, Mingote S, Correa M, Salamone JD: Accumbens dopamine and the regulation of effort in food-seeking behavior: modulation of work output by different ratio or force requirements. Behav. Brain Res. 151, 83-91 (2004).

68. Mingote S, Weber SM, Ishiwari K, Correa M, Salamone JD: Ratio and time requirements on operant schedules: effort-related effects of nucleus accumbens dopamine depletions. Eur. J. Neurosci. 21, 1749-1757 (2005).

69. Wakabayashi KT, Fields HL, Nicola SM: Dissociation of the role of nucleus accumbens dopamine in responding to reward-predictive cues and waiting for reward. Behav. Brain Res. 154, 19-30 (2004).

70. Aberman JE, Ward SJ, Salamone JD: Effects of dopamine antagonists and accumbens dopamine depletions on time-constrained progressive-ratio performance. Pharmacol. Biochem. Behav. 61, 341-348 (1998).

71. Hamill S, Trevitt JT, Nowend KL, Carlson BB, Salamone JD: Nucleus accumbens dopamine depletions and time-constrained progressive ratio performance: effects of different ratio requirements. Pharmacol. Biochem. Behav. 64, 21-27 (1999).
72. Salamone JD, Wisniecki A, Carlson BB, Correa M: Nucleus accumbens dopamine depletions make animals highly sensitive to high fixed ratio requirements but do not impair primary food reinforcement. Neuroscience 105, 863-870 (2001).

73. Salamone JD, Cousins MS, Bucher S: Anhedonia or anergia? Effects of haloperidol and nucleus accumbens dopamine depletion on instrumental response selection in a T-maze cost/benefit procedure. Behav. Brain Res. 65, 221-229 (1994).

74. Cousins MS, Atherton A, Turner L, Salamone JD: Nucleus accumbens dopamine depletions alter relative response allocation in a T-maze cost/benefit task. Behav. Brain Res. 74, 189-197 (1996).

75. Mott, AM, Nunes EJ, Collins LE et al.: The adenosine $\mathrm{A}_{2 \mathrm{~A}}$ antagonist MSX-3 reverses the effects of the dopamine antagonist haloperidol on effort-related decision making in a T-maze cost/benefit procedure. Psychopharmacology 204, 103-112 (2009).

76. Correa M, Pardo M, Hockemeyer J, Müller CE, Salamone JD: Dopamine $\mathrm{D}_{2}$ antagonism increases selection of less effortful food-seeking behavior in a T-maze procedure in mice: reversal of the motivational impairment with adenosine antagonists. Presented at: Neuroscience Meeting Planner Program Number 285.6. Society for Neuroscience, Chicago, IL, USA (2009).

77. Salamone JD, Correa M, Farrar AM, Nunes EJ, Pardo M: Dopamine, behavioral economics, and effort. Front Behav. Neurosci. 3, 13 (2009).

- Reviews the literature on effort-related functions of dopamine from the perspective of neural and behavioral economics.

78. Salamone JD, Farrar AM, Font L et al:: Differential actions of adenosine $A_{1}$ and $A_{2 A}$ antagonists on the effort-related effects of dopamine $\mathrm{D}_{2}$ antagonism. Behav. Brain Res. 201, 216-222 (2009).

79. Cagniard B, Balsam PD, Brunner D, Zhuang X: Mice with chronically elevated dopamine exhibit enhanced motivation, but not learning, for a food reward. Neuropsychopharmacology 31 , 1362-1370 (2006).

- Focuses on effort-related effects in genetically altered mice with reduced expression of the dopamine transporter. This paper presents data demonstrating that chronic elevation of extracellular dopamine leads to an increased selection of high-effort alternatives when mice are tested using choice procedures.

80. Cousins MS, Sokolowski JD, Salamone JD: Different effects of nucleus accumbens and ventrolateral striatal dopamine depletions on instrumental response selection in the rat. Pharmacol. Biochem. Behav. 46, 953-951 (1993). 
81. Cousins MS, Salamone JD: Nucleus accumbens dopamine depletions in rats affect relative response allocation in a novel cost/ benefit procedure. Pharmacol. Biochem. Behav. 49, 85-91 (1994).

82. Koch M, Schmid A, Schnitzler HU: Role of nucleus accumbens dopamine $\mathrm{D}_{1}$ and $\mathrm{D}_{2}$ receptors in instrumental and Pavlovian paradigms of conditioned reward. Psychopharmacology 152, 67-73 (2000).

83. Nowend KL, Arizzi M, Carlson BB, Salamone JD: $\mathrm{D}_{1}$ or $\mathrm{D}_{2}$ antagonism in nucleus accumbens core or dorsomedial shell suppresses lever pressing for food but leads to compensatory increases in chow consumption. Pharmacol. Biochem. Behav. 69, 373-382 (2001).

84. Farrar AM, Segovia KN, Randall PA et al:: Nucleus accumbens and effort-related functions: behavioral and neural markers of the interactions between adenosine $A_{2 A}$ and dopamine $\mathrm{D}_{2}$ receptors. Neuroscience 166(4), 1056-1067 (2010).

- Identifies nucleus accumbens as a brain locus at which dopamine and adenosine receptors interact to regulate effort-related processes. Moreover, it uses c-Fos immunoreactivity as a cellular marker of the direct interaction between drugs that act ondopamine $D_{2}$ and adenosine $A_{2 \mathrm{~A}}$ receptors.

85. Salamone J, Correa M, Font L, Pennarola A, Farrar AM, Mingote $S$ : Nucleus accumbens and the neurochemical interactions regulating effort-related processes. In: The Nucleus Accumbens: Neurotransmitters \& Related Behaviours. David HN (Ed.). Research Signpost, India, 195-217 (2008).

86. Fowler SC, Liou JR: Haloperidol, raclopride, and eticlopride induce microcatalepsy during operant performance in rats, but clozapine and SCH 23390 do not. Psychopharmacology 140, 81-90 (1998).

87. Floresco SB, Tse MT, Ghods-Sharifi S: Dopaminergic and glutamatergic regulation of effort- and delay-based decision making. Neuropsychopharmacology 33, 1966-1979 (2008).

- Demonstrates an important point regarding the role of effort and time as factors related to behavioral discounting procedures. The authors demonstrated that dopamine antagonism had an effect on effort discounting independently of any effects on delay discounting.

88. Bardgett ME, Depenbrock M, Downs N, Points M, Green L: Dopamine modulates effort-based decision making in rats. Behav. Neurosci. 123, 463-467 (2009).
89. Baldo BA, Kelley AE: Discrete neurochemical coding of distinguishable motivational processes: insights from nucleus accumbens control of feeding. Psychopharmacology 191, 439-459 (2007).

90. Niv Y, Daw ND, Joel D, Dayan P: Tonic dopamine: opportunity costs and the control of response vigor. Psychopharmacology 191, 507-520 (2007).

91. Phillips PE, Walton ME, Jhou TC: Calculating utility: preclinical evidence for cost-benefit analysis by mesolimbic dopamine. Psychopharmacology 191, 483-495 (2007).

92. Robbins TW, Everitt B: A role for mesencephalic dopamine in activation: commentary on Berridge (2006). Psychopharmacology (Berl.) 191, 433-437 (2007).

93. Walton ME, Kennerley SW, Bannerman DM, Phillips PE, Rushworth MF: Weighing up the benefits of work: behavioral and neural analyses of effort-related decision making. Neural Netw. 19, 1302-1314 (2006).

94. Walton ME, Bannerman DM, Rushworth MF: The role of rat medial frontal cortex in effort-based decision making. J. Neurosci. 22, 10996-11003 (2002).

95. Walton ME, Bannerman DM, Alterescu K, Rushworth MF: Functional specialization within medial frontal cortex of the anterior cingulate for evaluating effort-related decisions. J. Neurosci. 23, 6475-6479 (2003).

96. Schweimer J, Saft S, Hauber W: Involvement of catecholamine neurotransmission in the rat anterior cingulate in effort-related decision making. Behav. Neurosci. 119, 1687-1692 (2005).

97. Floresco SB, Ghods-Sharifi S: Amygdalaprefrontal cortical circuitry regulates effort-based decision making. Cereb. Cortex 17, 251-260 (2007).

98. Svenningsson P, Le Moine C, Fisone G, Fredholm BB: Distribution, biochemistry and function of striatal adenosine $\mathrm{A}_{2 \mathrm{~A}}$ receptors. Prog. Neurobiol. 59, 355-396 (1999).

99. Ferré S: An update on the mechanisms of the psychostimulant effects of caffeine. J. Neurochem. 105, 1067-1079 (2008).

100. Schiffmann SN, Jacobs O, Vanderhaeghen JJ: Striatal restricted adenosine $\mathrm{A} 2$ receptor (RDC8) is expressed by enkephalin but not by substance P neurons: an in situ hybridization histochemistry study. J. Neurochem. 57, 1062-1067 (1991).

101. DeMet EM, Chicz-DeMet A: Localization of adenosine $A_{2 A}$-receptors in rat brain with [3H]ZM-241385. Naunyn. Schmiedebergs Arch. Pharmacol. 366, 478-481 (2002).
102. Ferré S, Ciruela F, Canals M et al:: Adenosine $\mathrm{A}_{2 \mathrm{~A}}$-dopamine $\mathrm{D}_{2}$ receptor-receptor heteromers. Targets for neuro-psychiatric disorders. Parkinsonism Relat. Disord. 10, 265-271 (2004).

103. Ferré S: Adenosine-dopamine interactions in the ventral striatum. Implications for the treatment of schizophrenia. Psychopharmacology 133, 107-120 (1997).

104. Ferré S, Fredholm BB, Morelli M, Popoli P, Fuxe K: Adenosine-dopamine receptorreceptor interactions as an integrative mechanism in the basal ganglia. Trends Neurosci. 20, 482-487 (1997).

105. Ferré S, Popoli P, Gimenez-Llort L et al: Adenosine-dopamine interaction: implications for the treatment of Parkinson's disease. Parkinsonism Relat. Disord. 7 , 235-241 (2001).

106. Fink JS, Weaver DR, Rivkees SA et al.: Molecular cloning of the rat $\mathrm{A} 2$ adenosine receptor: selective co-expression with $\mathrm{D}_{2}$ dopamine receptors in rat striatum. Brain Res. Mol. Brain Res. 14, 186-195 (1992).

107. Fuxe K, Agnati LF, Jacobsen K et al.: Receptor heteromerization in adenosine $\mathrm{A}_{2 \mathrm{~A}}$ receptor signaling: relevance for striatal function and Parkinson's disease. Neurology 61, S19-S23 (2003).

108. Fuxe K, Ferré S, Genedani S, Franco R, Agnati LF: Adenosine receptor-dopamine receptor interactions in the basal ganglia and their relevance for brain function. Physiol. Behav. 92, 210-217 (2007).

109. Hauber W, Munkle M: Motor depressant effects mediated by dopamine $\mathrm{D}_{2}$ and adenosine $A_{2 A}$ receptors in the nucleus accumbens and the caudate-putamen. Eur. J. Pharmacol. 323, 127-131 (1997).

110. Hauber W, Neuscheler P, Nagel J, Muller CE: Catalepsy induced by a blockade of dopamine $\mathrm{D}_{1}$ or $\mathrm{D}_{2}$ receptors was reversed by a concomitant blockade of adenosine $\mathrm{A}_{2 \mathrm{~A}}$ receptors in the caudate-putamen of rats. Eur. J. Neurosci. 14, 1287-1293 (2001).

111. Wardas J, Konieczny J, Lorenc-Koci E: $\mathrm{SCH}$ 58261, an $\mathrm{A}_{2 \mathrm{~A}}$ adenosine receptor antagonist, counteracts parkinsonian-like muscle rigidity in rats. Synapse 41, 160-171 (2001).

112. Jenner P: Istradefylline, a novel adenosine $A_{2 A}$ receptor antagonist, for the treatment of Parkinson's disease. Expert Opin. Investig. Drugs 14, 729-738 (2005).

113. Morelli M, Pinna A: Interaction between dopamine and adenosine $A_{2 A}$ receptors as a basis for the treatment of Parkinson's disease. Neurol. Sci. 22, 71-72 (2002). 
114. Pinna A, Wardas J, Simola N, Morelli M: New therapies for the treatment of Parkinson's disease: adenosine $A_{2 \mathrm{~A}}$ receptor antagonists. Life Sci. 77, 3259-3267 (2005).

115. Correa M, Wisniecki A, Betz A et al.: The adenosine $A_{2 A}$ antagonist KF17837 reverses the locomotor suppression and tremulous jaw movements induced by haloperidol in rats: possible relevance to parkinsonism. Behav. Brain Res. 148, 47-54 (2004).

116. Salamone JD, Betz AJ, Ishiwari K et al.: Tremorolytic effects of adenosine $A_{2 A}$ antagonists: implications for parkinsonism. Front. Biosci. 13, 3594-3605 (2008).

117. Takahashi RN, Pamplona FA, Prediger RD: Adenosine receptor antagonists for cognitive dysfunction: a review of animal studies. Front. Biosci. 13, 2614-2632 (2008)

118. Correa M, Font L: Is there a major role for adenosine $\mathrm{A}_{2 \mathrm{~A}}$ receptors in anxiety? Front. Biosci. 13, 4058-4070 (2008).

119. Farrar AM, Pereira M, Velasco F, Hockemeyer J, Muller CE, Salamone JD: Adenosine $\mathrm{A}_{2 \mathrm{~A}}$ receptor antagonism reverses the effects of dopamine receptor antagonism on instrumental output and effort-related choice in the rat: implications for studies of psychomotor slowing. Psychopharmacology 191, 579-586 (2007).

120. Font L, Mingote S, Farrar AM et al.: Intra-accumbens injections of the adenosine $\mathrm{A}_{2 \mathrm{~A}}$ agonist CGS 21680 affect effort-related choice behavior in rats. Psychopharmacology 199, 515-526 (2008).

121. Mingote S, Font L, Farrar AM et al.: Nucleus accumbens adenosine $A_{2 A}$ receptors regulate exertion of effort by acting on the ventral striatopallidal pathway. J. Neurosci. 28, 9037-9046 (2008).

- Examined the effort-related functions of the ventral striatopallidal pathway with a combination of behavioral, pharmacological, anatomical and neurochemical approaches.

122. Barraco RA, Martens KA, Parizon M, Normile HJ: Adenosine $A_{2 a}$ receptors in the nucleus accumbens mediate locomotor depression. Brain Res. Bull. 31, 397-404 (1993).

123. Worden LT, Shahriari M, Farrar AM et al.: The adenosine $A_{2 A}$ antagonist MSX-3 reverses the effort-related effects of dopamine blockade: differential interaction with $\mathrm{D}_{1}$ and $\mathrm{D}_{2}$ family antagonists. Psychopharmacology 203, 489-499 (2003).

124. Collins LE, Galtieri DJ, Collins P et al.: Interactions between adenosine and dopamine receptor antagonists with different selectivity profiles: effects on locomotor activity. Behav. Brain Res. DOI: 10.1016/j. bbr.2010.03.003 (2010) (Epub ahead of print).

125. Ishiwari K, Madson LJ, Farrar AM et al.: Injections of the selective adenosine $\mathrm{A}_{2 \mathrm{~A}}$ antagonist MSX-3 into the nucleus accumbens core attenuate the locomotor suppression induced by haloperidol in rats. Behav. Brain Res. 178, 190-199 (2007).

126. Hettinger BD, Lee A, Linden J, Rosin DL: Ultrastructural localization of adenosine $\mathrm{A}_{2 \mathrm{~A}}$ receptors suggests multiple cellular sites for modulation of GABAergic neurons in rat striatum. J. Comp. Neurol. 431, 331-346 (2001).

127. Hillion J, Canals M, Torvinen M et al.: Coaggregation, cointernalization, and codesensitization of adenosine $A_{2 A}$ receptors and dopamine $\mathrm{D}_{2}$ receptors. J. Biol. Chem. 277, 18091-18097 (2002).

128. Azdad K, Gall D, Woods AS, Ledent C, Ferré S, Schiffmann SN: Dopamine $\mathrm{D}_{2}$ and adenosine $\mathrm{A}_{2 \mathrm{~A}}$ receptors regulate NMDAmediated excitation in accumbens neurons through $\mathrm{A}_{2 \mathrm{~A}}-\mathrm{D}_{2}$ receptor heteromerization. Neuropsychopharmacology 34, 972-986 (2009).

129. Ferré S, Quiroz C, Woods AS et al:: An update on adenosine $\mathrm{A}_{2 \mathrm{~A}}$-dopamine $\mathrm{D}_{2}$ receptor interactions: implications for the function of G-protein-coupled receptors. Curr. Pharm. Des. 14, 1468-1474 (2008).

130. Betz AJ, Vontell R, Valenta J et al:: Effects of the adenosine $A_{2 A}$ antagonist KW-6002 (istradefylline) on pimozide-induced oral tremor and striatal c-Fos expression: comparisons with the muscarinic antagonist tropicamide. Neuroscience 163, 97-108 (2009).

131. Hauber W, Sommer S: Prefrontostriatal circuitry regulates effort-related decision making. Cereb. Cort. 19, 2240-2247 (2009).

- This paper used 'disconnection methods' to study the interaction between the prefrontal/anterior cingulate cortex and nucleus accumbens in effort-related decision making.

132. Farrar AM, Font L, Pereira M et al.: Forebrain circuitry involved in effort-related choice: injections of the $\mathrm{GABA}_{\mathrm{A}}$ agonist muscimol into ventral pallidum alters response allocation in food-seeking behavior. Neuroscience 152, 321-330 (2008).

133. Cheney T: Manic. Harper, NY, USA (2008).

134. Tylee A, Gastpar M, Lepine JP, Mendlewicz J: DEPRES II (Depression Research in European Society II): a patient survey of the symptoms, disability and current management of depression in the community. DEPRES Steering Committee. Int. Clin. Psychopharmacol. 14, 139-151 (1999).
135. Salamone JD, Correa M, Mingote SM, Weber SM, Farrar AM: Nucleus accumbens dopamine and the forebrain circuitry involved in behavioral activation and effort-related decision making: implications of understanding anergia and psychomotor slowing and depression. Curr. Psychiat. Rev. 2, 267-280 (2006).

136. Demyttenaere K, De Fruyt J, Stahl SM: The many faces of fatigue in major depressive disorder. Int. J. Neuropsychopharmacol. 8, 93-105 (2005).

137. Capuron L, Pagnoni G, Demetrashvili MF et al:: Basal ganglia hypermetabolism and symptoms of fatigue during interferon- $\alpha$ therapy. Neuropsychopharmacology 32 , 2384-2392 (2007)

138. Majer M, Welberg LA, Capuron L, Pagnoni G, Raison CL, Miller AH: IFN- $\alpha$-induced motor slowing is associated with increased depression and fatigue in patients with chronic hepatitis C. Brain Behav. Immun. 22, 870-880 (2008).

139. Yurgelun-Todd DA, Sava S, Dahlgren MK: Mood disorders. Neuroimaging Clin. N. Am. 17, 511-521 (2007).

140. Rogers D, Lees AJ, Smith E, Trimble M, Stern GM: Bradyphrenia in Parkinson's disease and psychomotor retardation in depressive illness. An experimental study. Brain 110 (Pt 3), 761-776 (1987).

141. Brown AS, Gershon S: Dopamine and depression. J. Neural Transm. Gen. Sect. 91, 75-109 (1993).

142. Caligiuri MP, Ellwanger J: Motor and cognitive aspects of motor retardation in depression. J. Affect. Disord. 57, 83-93 (2000).

143. Volkow ND, Chang L, Wang GJ et al: Association of dopamine transporter reduction with psychomotor impairment in methamphetamine abusers. Am. J. Psychiatry 158, 377-382 (2001)

144. Schmidt K, Nolte-Zenker B, Patzer J, Bauer M, Schmidt LG, Heinz A: Psychopathological correlates of reduced dopamine receptor sensitivity in depression, schizophrenia, and opiate and alcohol dependence. Pharmacopsychiatry 34, 66-72 (2001).

145. Rampello L, Nicoletti G, Raffaele R: Dopaminergic hypothesis for retarded depression: a symptom profile for predicting therapeutical responses. Acta Psychiatr. Scand. 84, 552-554 (1991).

146. Brody AL, Saxena S, Mandelkern MA, Fairbanks LA, Ho ML, Baxter LR: Brain metabolic changes associated with symptom factor improvement in major depressive disorder. Biol. Psychiatry 50, 171-178 (2001). 
147. Hickie I, Ward P, Scott E et al.: Neo-striatal rCBF correlates of psychomotor slowing in patients with major depression. Psychiatry Res. 92, 75-81 (1999).

148. Marin RS: Apathy: concept, syndrome, neural mechanisms, and treatment. Semin. Clin. Neuropsychiatry 1, 304-314 (1996).

149. Campbell JJ, Duffy JD: Treatment strategies in amotivated patients. Psychiatric Annals 27, 44-49 (1996).

150. Corcoran C, Wong ML, O’Keane V: Bupropion in the management of apathy. J. Psychopharmacol. 18, 133-135 (2004).

151. Powell JH, al-Adawi S, Morgan J, Greenwood RJ: Motivational deficits after brain injury: effects of bromocriptine in 11 patients. J. Neurol. Neurosurg. Psychiat. 60, 416-421 (1996).

152. Friedman JH, Brown RG, Comella C et al.: Fatigue in Parkinson's disease: a review. Mov. Disord. 22, 297-308 (2007).

153. Lapierre Y, Hum S: Treating fatigue. Internat. MS J. 14, 64-71 (2007).
154. Krupp LB, Alvarez LA, LaRocca NG, Scheinberg LC: Fatigue in multiple sclerosis. Arch. Neurol. 45, 435-437 (1988).

155. Telez N, Alonso J, Rio J et al.: The basal ganglia: a substrate for fatigue in multiple sclerosis. Neuroradiology 50, 17-23 (2008).

156. Duffy JD, Campbell J: Buproprion for the treatment of fatigue associated with multiple sclerosis. Psychosomatics 35, 170-171 (1994).

157. Paul RH, Brickman AM, Navia B et al.: Apathy is associated with volume of the nucleus accumbens in patients infected with HIV. J. Neuropsychiatry Clin. Neurosci. 17, 167-171 (2005).

158. Salamone JD: Involvement of nucleus accumbens dopamine in behavioral activation and effort-related functions. In: Dopamine Handbook. Iversen LL, Iversen SD, Dunnett SB, Bjorklund A (Eds). Oxford University Press, Oxford, UK, 286-300 (2010).

159. Paxinos G, Watson C: The Rat Brain in Stereotaxic Coordinates. Academic Press, NY, USA (1997).
160. Assadi SM, Yucel M, Pantelis C: Dopamine modulates neural networks involved in effort-based decision making. Neurosci. Biobehav. Rev. 33, 383-393 (2009).

161. Croxson PL, Walton ME, O’Reilly JX, Behrens TEJ, Rushworth MFS: Effort-based cost-benefit valuation in human brain. J. Neurosci. 29, 4531-4541 (2009).

162. Stahl SM: The psychopharmacology of energy and fatigue. J. Clin. Psychiatry 63, 7-8 (2002).

163. Salamone JD, Ishiwari K, Betz AJ et al.: Dopamine/adenosine interactions related to locomotion and tremor in animal models: possible relevance to parkinsonism. Parkinsonism Relat. Disord. 14, S130-S134 (2008).

164. Howes OD, Egerton A, Allan V, McGuire P, Stokes P, Kapur S: Mechanisms underlying psychosis and antipsychotic treatment response in schizophrenia: insights from PET and SPECT imaging. Curr. Pharm. Des. 15, 2550-2559 (2009). 